\title{
Neumonia Grave Adquirida en la Comunidad en pacientes pediátricos en UCl: serie de casos. Hospital Docente Materno Infantil Dr A.A.Aballi. Enero de 2014 a septiembre de 2016
}

\author{
María Elena Álvarez-Andrade* \\ Mercedes Rubén-Quesada** \\ Dayrel Cuevas-Álvarez*** \\ Laura Margarita Sánchez-Pérez $z^{* * *}$
}

*Médico Pediatra e Intensivista. Magister en Enfermedades Infecciosas. Doctora en Ciencias Médicas. Profesora Titular. Investigadora FCM-H Julio Trigo López. Unidad de Cuidados Intensivos Pediátricos. Hospital Docente Materno Infantil Dr. A. A. Aballí. La Habana. Cuba.

**Licenciada en Matemática. Doctora en Ciencia. Profesora e Investigadora Titular. Victoria de Girón. La Habana. Cuba.

***Médico Especialista en Medicina Intensiva. Profesor Instructor. Unidad de Cuidados Intermedios. Hospital Docente Clínico Quirúrgico Miguel Enrique. La Habana. Cuba.

****Médico Pediatra. Especialista en Medicina General Integral. Magister en Urgencias Médicas. Profesora Asistente. Unidad de Cuidados Intensivos Pediátrico. Hospital Docente Materno Infantil Dr. A. A. Aballí. La Habana. Cuba.

Correspondencia: Dra. María Elena Álvarez. Independencia Este 808. Reparto Ricabal. Guanabacoa. La Habana. Cuba. Correo electrónico: pollyalvarez@yahoo.es

RESUMEN

Introducción: la Neumonía Adquirida en la Comunidad constituye un serio problema de salud con elevada morbi-mortalidad infantil en el mundo, alcanza un $8 \%$ de hospitalizaciones y la letalidad en esos casos puede llegar al $4 \%$. El conocimiento de pruebas hematológicas analíticas, a pesar de ser inespecíficas, apoya en la orientación diagnóstica para un mejor manejo inicial de las formas graves de esta enfermedad. Objetivo: identificar las características epidemiológicas y las alteraciones de pruebas analíticas en pacientes pediátricos con Neumonía Grave Adquirida en la Comunidad, en la Unidad de Cuidados Intensivos Pediátricos del Hospital Docente Materno Infantil Dr. A.A.Aballí. Materiales y Métodos: se realizó una investigación descriptiva, tipo serie de casos en niños ingresados con neumonía grave adquirida en la comunidad en la Unidad de Cuidados Intensivos Pediátricos del Hospital Docente Materno Infantil Dr. A.A.Aballí. Resultados: predominó la edad mayor de un año y el sexo femenino, la principal complicación fue el derrame pleural, el $27,4 \%$ tuvo una estadía superior a siete días, en el conteo de neutrófilos, la velocidad de sedimentación globular y la proteína C reactiva positiva predominaron los valores superiores a la media, la mayoría de los pacientes presentaron hipoalbuminemia. Conclusiones: la prevalencia fue mayor entre 1 y 4 años de edad, el derrame pleural fue la complicación más común, y la alteración de todas las pruebas hematológicas analíticas realizadas al ingreso fue prevalente. MÉD.UIS. 2017;30(3):51-8.

Palabras clave: Neumonía. Unidades de Cuidados Intensivos. Pediatría. Pruebas hematológicas Serious Pneumonia Acquired in the Community in pediatric ICU patients: case series.
Maternal and Child Teaching Hospital Dr. A.A.Aballi. January 2014 to September 2016

ABSTRACT

Introduction: community Acquired Pneumonia is a serious health problem with high worldwide infant morbidity and mortality, reaching $8 \%$ of hospitalizations and, in these cases, lethality can reach $4 \%$. Despite being non-specific, the knowledge of analytical hematological tests supports the diagnostic orientation for a better initial management of this disease's severe forms Objective: to identify the epidemiological characteristics and laboratory tests abnormalities in pediatric patients with severe Community Acquired Pneumonia at the Pediatric Intensive Care Unit of the Teaching Maternity- Child Hospital Dr. A.A. Aballí. Materials and Method: a descriptive investigation was carried out, with a series of cases in hospitalized children with severe Community Acquired Pneumonia at the Pediatric Intensive Care Unit of the Teaching Maternity- Child Hospital Dr. A.A. Aballí. Results: prevalence was greater in over one year old children and in female patients, the main complication was pleural effusion, $27.4 \%$ had a stay of more than seven days; neutrophil count, erythrocyte sedimentation rate, and protein C Reactive positive values were above the average and most of the patients presented hypoalbuminemia. Conclusions: prevalence was higher between 1 and 4 years, pleural effusion was the most common complication, and the alteration of all hematological tests performed at admission was prevalent. MÉD.UIS. 2017;30(3):51-8.

Keywords: Pneumonia. Intensive Care Units. Pediatrics. Hematological tests.

Artículo recibido el 18 de febrero de 2017 y aceptado para publicación el 26 de julio de 2017 
¿Cómo citar este artículo?: Álvarez-Andrade M, Rubén-Quesada M, Cuevas-Álvarez D, SánchezPérez L. Neumonía Grave Adquirida en la Comunidad en pacientes pediátricos en UCl: serie de casos. Hospital Docente Materno Infantil Dr A.A.Aballí. Enero de 2014 a septiembre de 2016. MÉD. UIS. 2017;30(3):51-8.

\section{INTRODUCCIÓN}

Las infecciones respiratorias agudas se hallan entre las principales causas de defunción en la primera infancia, representando el primer motivo de enfermedad y consulta a los servicios de salud a nivel mundial'. En la actualidad existe una prevalencia de la Neumonía Adquirida en la Comunidad (NAC) de hasta un $60 \%$ en la población infantil2.

Según un informe de la OMS la neumonía es la principal causa individual de mortalidad infantil en todo el mundo, se calcula que la neumonía fue responsable de la muerte de 920136 niños menores de 5 años en 2015, lo que supone el $15 \%$ de todas las defunciones de menores de 5 años 3 .

La incidencia de NAC en niños hospitalizados es variable y oscila entre 3 y 10,9 por mil menores de cinco años en los estudios contemporáneos europeos y norteamericanos ${ }^{2}$. En Cuba, la atención médica por enfermedades respiratorias en menores de 5 años sobrepasó el millón de consultas, con una tasa de mortalidad por influenza y neumonía de 0,3 por mil nacidos vivos para los menores de un año e igual cifra por diez mil niños de 1 a 4 años. Al cierre de 2015 la influenza y neumonía se ubicaron entre las primeras cinco causas de muerte en ambos grupos etarios ${ }^{4}$.

En el caso de la Neumonía Grave Adquirida en la Comunidad (NGAC) representa un motivo de ingreso importante en las Unidades de Cuidados Intensivos Pediátricos (UCIP), y se reporta en múltiples ocasiones como una de las principales causas de admisión y de estadía prolongada en esos servicios ${ }^{5}$.

El reconocimiento precoz de la posible causa etiológica de la NAC para identificar potenciales complicaciones de las neumonías bacterianas y su evolución hacia un estado de mayor gravedad, requiere de la valoración múltiple de diferentes aspectos entre los cuales la evaluación clínica del niño, apoyada en diversos estudios complementarios, es de primordial importancia.
Dentro de los exámenes posibles a realizar, con el propósito antes descrito, se mencionan las pruebas hematológicas inespecíficas y los reactantes de fase aguda como el recuento de leucocitos, el conteo de neutrófilos, la velocidad de sedimentación globular, la Proteína $C$ reactiva y la procalcitonina, entre otras pruebas hematológicas, las cuales han sido motivo de numerosos estudios ${ }^{6,7}$.

Estas pruebas hematológicas analíticas no ofrecen una evidencia directa de la implicación causal (bacteriana o viral). Sin embargo, pueden servir de apoyo en el posible diagnóstico etiológico de la NAC y también pueden ser útiles como parámetro en la evolución de los casos $^{2-8}$.

Por la importancia de conocer las particularidades de la NGAC en el contexto hospitalario, esta investigación se propuso identificar las características epidemiológicas y las alteraciones de pruebas analíticas en pacientes pediátricos con Neumonía Grave Adquirida en la Comunidad, en la Unidad de Cuidados Intensivos Pediátricos del Hospital Docente Materno Infantil Dr. A.A. Aballí.

\section{Materiales y mÉtodos}

Se realizó una investigación descriptiva, prospectiva y de corte longitudinal tipo serie de casos en niños ingresados con NGAC en la Unidad de Cuidados Intensivos Pediátricos del Hospital Materno Infantil Dr Ángel Arturo Aballí, en La Habana, durante el período de enero de 2014 a septiembre de 2016.

La población estuvo integrada por todos los pacientes con NGAC admitidos en la UCIP durante el tiempo que se llevó a cabo el estudio y correspondió a 243 casos. De estos participaron en la investigación 102 pacientes que cumplieron con los criterios de inclusión: niños de un mes hasta cuatro años, sin enfermedades crónicas asociadas conocidas por los antecedentes patológicos o evidenciados al examen físico (cardiopatías congénitas, enfermedades pulmonares crónicas, enfermedades malignas y enfermedades neuromusculares) y estadía en UCIP 
mayor a 48 horas. Los criterios de exclusión fueron los casos que requirieron ser trasladados a UCIP de otras instituciones previo al término de su posible estadía.

Fue considerada para esta investigación la NGAC cuando el paciente que ingresó con el diagnóstico de neumonía no fue hospitalizado en los 7-14 días previos al comienzo de los síntomas 0 cuando éstos comenzaron en las primeras 48 horas desde su hospitalización y que presentaron criterios de ingreso en cuidados intensivos por las manifestaciones fisiopatológicas de los casos (independientes a que fueran complicadas o no) según alteraciones clínicas, gasométricas y/o radiológicas (Ver figura 1 ).

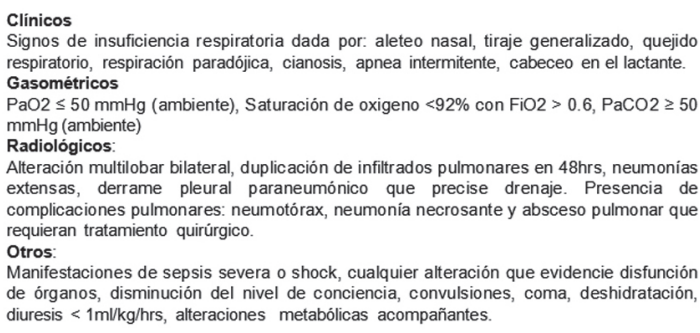

Figura 1. Admitidos en la ucip los pacientes con los siguientes criterios de gravedad

Fuente: Grupo Nacional de Pediatría, Grupo Nacional de infectología, Comisión Nacional de Infecciones Respiratorias Agudas y Sociedad Cubana de Pediatría, Consenso nacional para el diagnóstico y tratamiento de la neumonía adquirida en la comunidad en pediatría, Cuba, 2013. ISBN 978-306-1244-7.

La fuente de información fue el documento clínico del paciente de donde se obtuvieron los datos primarios necesarios reflejados por el médico de asistencia. Los investigadores hacen la recolección de la información, la verificación del dato primario y la clasificación de los casos que cumplían con los requisitos para integrar la serie de estudio. Dicha información fue acumulada en una ficha de recopilación de datos diseñada para estos efectos.

La realización de los estudios hematológicos se efectuó al ingreso del paciente a la UCIP. Los casos fueron seguidos hasta su egreso del servicio.

\section{OPERACIONALIZACIÓN DE VARIABLES}

\section{Variables generales}

- Edad: edad cronológica al ingreso en UCIP expresada en años. Categorizada en menor de un año o de uno a cuatro años.
- Sexo: condición biológica que determina el género. Categorizada en femenino y masculino.

- Desnutrido: índice de peso para la Talla < al 3 p según los percentiles descritos en las tablas cubanas de crecimiento y desarrollo (Ver Figura 2). Categorizada Sí o No.

Normal o típico: Entre el percentil 10 y el 90. Delgado: Entre el percentil 3 y por debajo del 10 Probablemente desnutrido: Por debajo del percentil 3 Sobrepeso: Por encima del percentil 90 y hasta el 97 Probablemente obeso: Por encima del percentil 97.

Figura 2. Percentiles según las cubanas de crecimiento y desarrollo para el estado nutricional de la poblacion pediatrica. según indicador peso para la talla $(p / t)$

Fuente: Gutiérrez JA, Berdasco A, Esquivel M, Jiménez JM, Posada E, Romero JM, et al. Crecimiento y desarrollo. En Autores Cubanos, editores. Pediatría T-I- La Habana:Ecimed. 2006: 27-58.

- Complicación: situación clínica y/o radiológica relacionada con la NAC, diagnosticada inicialmente por el médico de asistencia, reflejadas en el documento clínico del paciente y verificadas por los investigadores. Categorizada en Sí o No.

- Tipo de complicaciones: pulmonares (derrame pleural, absceso pulmonar, neumotórax neumatocele, atelectasia). Extra pulmonares (sepsis severa, shock)

- Estadía: tiempo en días que transcurrió entre el ingreso y el egreso de cuidados intensivos. A partir de la media de estadía calculada (media = 7,2 días), se tomó como punto de corte el número absoluto más cercano (7 días). Categorizada en $\leq 7$ días y >7 días.

\section{Variables de las pruebas hematológicas analíticas}

- Conteo de leucocitos: se realizó el conteo total de leucocitos según la técnica habitual9

A partir de la media calculada (media $=15$ 599), se tomó como punto de corte su aproximación a 15600 . Categorizada en $\leq 15600$ y $>15600$.

- Conteo de neutrófilos: se realizó el conteo total de neutrófilos según la técnica habitual ${ }^{9}$. Fue calculada la media que correspondió con 10451. Se categorizó en < $10451 \mathrm{y} \geq 10451$.

- Velocidad de Sedimentación Globular (VSG): según la técnica habitual ${ }^{9}$, expresada en $\mathrm{mm} / \mathrm{h}$. Fue calculada la media que correspondió con 82,7 , se tomó como punto de corte su aproximación a 83. Categorizada en $<83$ y $\geq 83$

- Proteína C Reactiva (PCR): reactante de la fase 
aguda positiva determinado por método de aglutinación semicuantitativo (Reactivo Látex Helfa-Finlay, fue considerado para este estudio como positivo títulos superiores a dilución 1:4, que corresponde a valores mayores a $12 \mathrm{mcg} / \mathrm{ml}$ ). Categorizada en positiva y negativa.

- Albúmina sérica: se obtuvo a través del método colorimétrico de verde bromocresol. Su punto de corte se estableció en $35 \mathrm{~g} / \mathrm{L}$. Categorizada en $<35 \mathrm{~g} / \mathrm{L}$ (hipoalbuminemia) $\mathrm{y} \geq 35 \mathrm{~g} / \mathrm{L}$ (normoalbuminemia).

\section{ANÁLISIS ESTADÍSTICOS}

Para el análisis descriptivo de los resultados se emplearon como medidas de resumen la frecuencia absoluta (números absolutos) y relativas (porcientos con sus intervalos de confianza al $95 \%$ en las variables hematológicas analíticas). Para las variables conteo de leucocitos, conteo de neutrófilos y VSG se decidió buscar un punto de corte lo más homogéneo posible dado los diferentes valores encontrados en la literatura, por lo cual se calculó la media y desviación estándar (valores superiores a la media fueron considerados alterados). De igual forma se calculó media y desviación para la variable estadía (Ver Tabla 1). A partir de ese punto de corte se accedió a variables dicotómicas.

Tabla 1. media y desviación Estándar en las variables donde fueron calculadas

\begin{tabular}{|c|c|c|}
\hline \multicolumn{3}{|c|}{$\begin{array}{c}\text { Media y desviación estándar en las variables } \\
\text { donde fueron calculadas }\end{array}$} \\
\hline Variables & Media & $\begin{array}{c}\text { Desviación } \\
\text { Estándar }\end{array}$ \\
\hline $\begin{array}{c}\text { Conteo de } \\
\text { leucocitos }\end{array}$ & 15598,73 & $\pm 9261,4$ \\
\hline $\begin{array}{c}\text { Conteo de } \\
\text { neutrofilos }\end{array}$ & 10451 & $\pm 6845,3$ \\
\hline VSG & 82,76 & $\pm 27,2$ \\
\hline Estadio en terapia & 7,2 & $\pm 5,1$ \\
\hline
\end{tabular}

Fuente: Autor.

\section{Resultados}

En la Tabla 1 se presentan las características generales de la muestra. Fueron evaluados 102 casos de los cuales $77(75,5 \%)$ fueron mayores de un año, $56(54,9 \%)$ eran del sexo femenino, $12(11,8 \%)$ presentaron desnutrición, se complicaron 74 (72,5 $\%)$. El derrame pleural con 70 casos (94,5\%) fue la principal complicación. La sumatoria de todas las complicaciones no coincide con el total de casos complicados ya que hubo pacientes que presentaron más de una complicación. El 27,4 \% tuvo una estadía mayor a siete días.

En la Tabla 2 se muestra las pruebas hematológicas analíticas, donde se observa el conteo de leucocitos $\geq 15600$ en $67,7 \%$; el conteo de neutrófilos $\geq 10451$ en $54,9 \%$; la VSG $\geq 83$ en $56,9 \%$; la PCR positiva en el $67,6 \%$ y, por último, la albúmina sérica inferior a $35 \mathrm{~g} / \mathrm{L}$ en el $61,7 \%$. En todos los casos los valores porcentuales estaban contenidos en el intervalo de confianza al $95 \%$.

Tabla 1. Características generales de la muestra

\begin{tabular}{|c|c|c|c|}
\hline \multicolumn{2}{|c|}{ Variables } & \multirow{2}{*}{$\begin{array}{c}\text { Casos } \\
\text { (102) } \\
25\end{array}$} & \multirow{2}{*}{$\begin{array}{r}\% \\
24,5\end{array}$} \\
\hline & $<1$ & & \\
\hline & $\geq 1$ & 77 & 75,5 \\
\hline \multirow{2}{*}{ Sexo } & Femenino & 46 & 45,1 \\
\hline & Masculino & 56 & 54,9 \\
\hline \multirow{2}{*}{ Desnutrido } & $\mathrm{Si}$ & 12 & 11,8 \\
\hline & No & 90 & 88,2 \\
\hline \multirow{2}{*}{ Complicaciones } & $\mathrm{Si}$ & 74 & 72,5 \\
\hline & No & 28 & 27,5 \\
\hline \multirow{4}{*}{$\begin{array}{c}\text { Tipo de } \\
\text { complicaciones* }\end{array}$} & $\begin{array}{c}\text { Derrame } \\
\text { pleural }\end{array}$ & 70 & 94,5 \\
\hline & Abceso & 13 & 17,6 \\
\hline & Neumatocele & 10 & 13,5 \\
\hline & Otras & 5 & 6,7 \\
\hline \multirow{2}{*}{ Estadía } & $\leq 7$ días & 74 & 72,6 \\
\hline & $>7$ días & 28 & 27,4 \\
\hline
\end{tabular}

*porcentaje del total de los casos complicados Fuente: Base de datos de la investigación.

\section{Discusión}

La muerte por NAC es mínima en los pacientes pediátricos de los países desarrollados. Sin embargo, no ocurre así en los países en desarrollo en los cuales alcanza mayor incidencia y mortalidad, lo cual hace que la NAC constituya un problema de salud como se reporta en América Latina ${ }^{8}$.

En otras zonas geográficas como Sudán existe un $4 \%$ de mortalidad en niños menores de 5 años con NAC admitidos en unidades de emergencia. En Egipto, una investigación en pacientes de hasta cinco años con NAC se reporta que el $26,7 \%$ de los casos fallecieron. 
Tabla 2. Casos según pruebas hematológicas analíticas

\begin{tabular}{|c|c|c|c|c|c|c|c|c|c|}
\hline \multirow{2}{*}{ Variables } & \multicolumn{2}{|c|}{$\leq 7$ días } & \multicolumn{2}{|c|}{ > 7 días } & \multicolumn{2}{|c|}{ Total (102) } & \multirow{2}{*}{$p$} & \multirow{2}{*}{ OR } & \multirow{2}{*}{ IC al $95 \%$} \\
\hline & Casos & $\%$ & Casos & $\%$ & Casos & $\% *$ & & & \\
\hline \multicolumn{10}{|l|}{ C. Leucocitos ${ }^{\dagger}$} \\
\hline$<15600$ & 23 & 69,7 & 10 & 30,3 & 33 & 32,3 & & & \\
\hline$\geq 15600$ & 51 & 73,9 & 18 & 26,1 & 69 & 67,7 & 0,834 & - & - \\
\hline \multicolumn{10}{|l|}{ C. Neutrofitos ${ }^{\dagger}$} \\
\hline$<10451$ & 39 & 84,8 & 7 & 15,2 & 46 & 45,1 & & & \\
\hline$\geq 10451$ & 35 & 62,5 & 21 & 37,3 & 56 & 54,9 & 0,022 & 3,3 & $1,26-8,81$ \\
\hline \multicolumn{10}{|l|}{ VSG $^{+}$} \\
\hline$<83$ & 39 & 88,6 & 5 & 11,4 & 44 & 43,1 & & & \\
\hline$\geq 83$ & 35 & 60,3 & 23 & 29,7 & 58 & 56,9 & 0,003 & 5,1 & $1,75-14,9$ \\
\hline \multicolumn{10}{|l|}{$\mathrm{PCR}^{\Omega}$} \\
\hline Negativo & 30 & 90,9 & 3 & 9,1 & 33 & 32,4 & & & \\
\hline Positivo & 44 & 63,8 & 25 & 36,2 & 69 & 67,6 & 0,008 & 5,6 & $1,57-20,5$ \\
\hline \multicolumn{10}{|l|}{ Albumina } \\
\hline$<35$ & 38 & 60,3 & 25 & 39,7 & 63 & 61,7 & & & \\
\hline$\geq 35$ & 36 & 92,3 & 3 & 7,7 & 39 & 38,3 & 0,001 & 7,8 & $2,10-28,4$ \\
\hline
\end{tabular}

*porcentaje del total.

${ }^{\dagger}$ el punto de corte corresponde con la media.

$\Omega$ PCR positiva según valores del método empleado, dilución $1: 4$, mayor a $12 \mathrm{mcg} / \mathrm{ml}$

Fuente: Base de datos de la investigación.

En los casos evaluados en esta investigación no hubo decesos, a pesar de que, en Cuba, el Consenso Nacional para el Diagnóstico y Tratamiento de la NAC en Pediatría de 2013 reconoce que la neumonía constituye la causa más frecuente de muerte por enfermedades infecciosas en el grupo de edad menores de cinco años, como fue reseñado en un reciente trabajo sobre carga hospitalaria y poblacional de las neumonías adquiridas en la comunidad en niños de esas edaes ${ }^{11}$. Por lo que los resultados en este estudio pudieran ser explicados dado lo limitada de la serie.

La edad como variable biológica es importante en la etapa pediátrica por el rápido desarrollo fisiológico que alcanza el niño durante los primeros años de vida. Flores Nava y colaboradores, reportan que en pacientes pediátricos con NAC ingresados en un centro hospitalario en México, la edad media de los casos correspondió a 15,8 meses ${ }^{12}$.

Rodríguez Cutting y colaboradores, encontraron que el $61 \%$ de niños con NGAC procedentes de cuidados intensivos y otros provenientes del cuerpo de guardia, tenían edades entre uno y cuatro años ${ }^{13}$.

De igual forma se describe el predominio de ese grupo de edad en dos estudios descriptivos que agruparon a 247 niños donde todos los casos eran portadores de
NGAC ${ }^{14,15}$. En esta investigación hubo semejanza con los resultados antes descritos, al ser más los pacientes mayores de un año que los lactantes.

En la mayoría de la literatura revisada relacionada con la población pediátrica se encuentra un predominio de varones en los pacientes portadores de la NAC, sin una justificación causal explícita ${ }^{2,14,16}$. Una ligera superioridad del sexo femenino, como ocurrió en esta investigación, solo aparece descrita en menor número de trabajos que abordan el tema en niños ${ }^{15}$.

Según la $\mathrm{OMS}^{3}$, varios factores se han asociado con mayor incidencia y severidad de la NAC en el niño; entre ellos se destaca la desnutrición, que se encuentra entre los factores del huésped capaz de empeorar el pronóstico. En un estudio realizado en India en pacientes de entre 2 y 59 meses con neumonía, la desnutrición estuvo presente en el $28 \%$ de los casos y en ellos hubo un curso más largo en su recuperación con mayor estadía hospitalaria ${ }^{17}$. En Cuba, la desnutrición en NGAC en UCIP se reporta por Adrisana y colaboradores en el $8,6 \%{ }^{18}$, Brito Bartumeut y colaboradores en población con características similares encontró el 14,2 \% ${ }^{14}$. En otra serie de niños con NAC hospitalizados también en Cuba los casos de desnutridos representaron el $4 \%{ }^{19}$. 
En este estudio se evidenció de igual forma cifras bajas de desnutrición.

Según las Sociedades Españolas de Infectología Pediátrica y de Neumología, así como el Comité Asesor de Vacunas de la Asociación Española de Pediatría $^{20}$ en los últimos 10 a 15 años se ha venido observando una tendencia creciente, superior a la descrita previamente, en la incidencia de neumonías complicadas, tanto con derrame pleural como de formas necrosantes. Esta tendencia se une a un ligero desplazamiento de la edad de aparición de estas formas complicadas que, anteriormente, era más frecuente en menores de 2-3 años, pero en los últimos años predominan en niños entre los 2 y 5 años.

El derrame pleural ha sido constatado hasta en el $40 \%$ de niños con NAC que se encuentran hospitalizados y el absceso pulmonar, aunque es una complicación menos frecuente, ha tenido incremento en su incidencia ${ }^{21}$.

En Cuba, una serie de casos que incluyó 176 niños con NAC el derrame pleural se presentó en más de dos tercios de los niños, seguido por el absceso pulmonar'13. Por su parte, Brito Bartumeu y colaboradores ${ }^{14}$ reportan el derrame pleural, el absceso pulmonar y el neumatocele como las principales complicaciones, todas las cuales agravan la evolución del paciente. Los resultados en este estudio fueron semejantes a los descritos previamente si se tiene en cuenta que el derrame pleural destacó como la principal complicación.

La estadía puede ser considerada como indicador de la evolución del paciente en cuidados intensivos y desempeña un papel importante en el pronóstico de los casos. Mosleh y colaboradores ${ }^{5}$, reportan en pacientes menores de cinco años con neumonía estudiados en el departamento de emergencia en un hospital del Cairo, Egipto, que un mayor tiempo de estadía presentó asociación independiente con la mortalidad, comportándose la mayor estancia hospitalaria como predictor de muerte.

En la bibliografía revisada ${ }^{12,14,22}$, se describe como promedio una media variada y discretamente inferior de días en UCIP en relación con los resultados de esta investigación, lo cual puede estar dado por la diversidad de las complicaciones, así como la gravedad de los casos evaluados.

El recuento de leucocitos, VSG y la PCR, entre otras, son consideradas como reactantes de fase aguda con utilidad limitada dado que no tienen suficiente sensibilidad y especificidad por sí solas para diferenciar la NAC de causa bacteriana, pero su correcto empleo podría ser de ayuda en la aproximación diagnóstica para conocer la etiología y/o gravedad de las $\mathrm{NAC}^{2,8}$.

La leucocitosis mayor a 15 000/mm3 con desviación a la izquierda, clásicamente se ha descrito que sugiere una etiología bacteriana de la neumonía, aunque dichas determinaciones no son específicas aisladamente. Por su parte, se reporta que el valor del número de neutrófilos como marcador de infección bacteriana tiene sensibilidad discreta y sólo valores elevados permitirían una predicción aceptable².

En pruebas analíticas realizadas a niños ingresados con NAC en un hospital de Salamanca en España, se reportó el $42 \%$ con leucocitosis mayor de 12000 y neutrofilia mayor de 6000 en el 59\%22. En México, donde fueron evaluados 207 casos en menores de 7 años también con NAC, destaca que los valores medios de la cuenta de leucocitos totales fueron de 12 084 y la cuenta de neutrófilos totales de $6201^{12}$, valores que aunque inferiores a los descritos en el presente estudio, no pueden ser comparados por la diferencia de escenarios donde se han realzado si se tiene en cuenta que la casuística empleada en el trabajo previo citado fue de niños con NAC admitidos en la división de pediatría del hospital. El citado estudio no hace referencia a que estuvieran en cuidados intensivos como ocurrió en esta investigación, lo que puede hacer pensar que existan diferencias en la gravedad de la NAC entre ambas series.

En el caso de la PCR, aunque no está indicada de forma rutinaria en el manejo de las NAC no complicadas, su positividad podría orientar hacia una etiología bacteriana y a una mayor gravedad de la enfermedad ${ }^{23}$.

Korppi y colaboradores ${ }^{24}$ en 132 casos encontraron que con una combinación de reactantes de la fase aguda donde se incluyen la PCR elevada, el conteo de leucocitos mayor a 17310 y la VSG por encima de 63 la probabilidad de la neumonía bacteriana a neumococo en el niño fue 1,74 veces mayor en relación a cuando no estaba presente dicha combinación, con una sensibilidad y especificidad discreta de $61 \%$ y $65 \%$, respectivamente.

Flood y colaboradores evaluaron 1230 pacientes pediátricos con NAC agrupados en un meta-análisis 
que incluyo ocho estudios, estos autores demostraron que una elevación de la PCR entre 35 y $60 \mathrm{mg} / \mathrm{l}$ fue significativamente asociada 2,58 veces más en NAC bacteriana, más propensas a la gravedad?

Las pruebas analíticas, a pesar de las limitaciones previamente mencionadas, dado su asequibilidad y bajo costo pueden ser útiles en nuestro medio para considerar la evolución de los casos siempre que sean interpretadas a partir del criterio clínico previo. En esta investigación el conteo de neutrófilos, la velocidad de sedimentación globular y la proteína $C$ reactiva tuvieron una relación significativa con mayores días de evolución del paciente en UCIP.

Con respecto a la albúmina sérica, la respuesta de la fase aguda frente a la injuria por el estrés metabólico frena la síntesis de esta proteína con su consecuente disminución, y se le considera como reactante negativa de la fase aguda.

Tiwari y colaboradores, en 435 casos ingresados en UCIP demostró que la hipoalbuminemia al ingreso fue un indicador significativo de morbilidad y mortalidad en niños gravemente enfermos. Los casos con hipoalbuminemia presentaron una mayor gravedad y estadía en UCIP en relación con aquellos con valores de albúmina normal al ingreso ${ }^{25}$.

En Brasil, al evaluar 271 niños ingresados en UCIP incluidos en un estudio de cohorte, se demostró que la hipoalbuminemia al ingreso estuvo asociada a mayores días de estadía, mayor mortalidad y más duración de la ventilación mecánica, independiente al estado nutricional ${ }^{26}$.

Viasus y colaboradores en un análisis observacional prospectivo en 3463 adultos hospitalizados con NAC muestran que los niveles disminuidos de albúmina sérica en las primeras 24 horas de admisión están asociados, con alta significación estadística, a una prolongada estadía en UCIP, y resultan útiles para identificar aquellos pacientes con mayor riesgo de complicaciones. Esos expertos concluyen en que la hipoalbuminemia es un buen marcador pronóstico en la $\mathrm{NAC}^{27}$.

También al evaluar 236 menores de cinco años de edad con diagnóstico de neumonía, en una investigación realizada en Egipto, se encontró que los no sobrevivientes tenían al ingreso niveles más bajo de albúmina en suero en comparación con los sobrevivientes para $\mathrm{p}<0,001^{5}$.
De igual forma, Prais y colaboradores al analizar el valor de albúmina en niños con neumonía complicada con derrame pleural ingresados en UCIP encuentran significativa hipoalbuminemia en ese grupo de pacientes $^{28}$. En esta investigación se encuentran semejanzas con los estudios previos mencionados al tener la hipoalbuminemia relación significativa con la estadía y ser esta última considerada como indicador de la evolución de los casos en UCIP.

\section{LIMITACIONES DE LA INVESTIGACIÓN}

No se describió el diagnóstico etiológico de la NAC dado el escaso crecimiento microbiológico obtenido en la serie estudiada. No fueron aplicadas escalas genéricas ni específicas de gravedad para la designación de esta condición ya que las mismas no han sido validadas previamente en el centro hospitalario para la población objeto de esta investigación. Por esa razón se decidió emplear los Criterios del Consenso para NAC vigentes en Cuba.

\section{Conclusiones}

La edad más frecuente en esta investigación fue la de mayores de un año, el sexo femenino tuvo discreta preponderancia, la desnutrición estuvo presente en una minoría de casos, las complicaciones aparecieron en casi la totalidad de la serie, entre la más frecuentes están el derrame pleural seguido por el abceso pulmonar y el neumatocele.

El conteo de neutrófilos, la VSG y la proteína C reactiva positiva tuvieron valores superiores a la media en más de la mitad de los casos evaluados, el mayor número de pacientes presentaron Hipoalbuminemia.

\section{RECOMENDACIONES}

Llevar a cabo futuros estudios con una mayor casuística y en los cuales sea evaluada la asociación entre las pruebas hematológicas analíticas y la evolución de los casos.

\section{Consideraciones ÉtICAS}

La investigación fue avalada por el Comité de Ética para las Investigaciones del Hospital Docente Materno Infantil Dr. A.A. Aballí de la Facultad de Medicina Julio Trigo López, Universidad de Ciencias Médicas de La Habana. Se obtuvo el consentimiento 
informado por parte de los padres o tutores representantes de los pacientes participantes.

\section{CONFLicto de INTERESES}

Los autores no manifiestan conflicto de interés.

\section{Referencias Bibliográficas}

1. World Health Organization, UNICEF. Global Action Plan for Prevention and control of Pneumonia (GAPP). Geneva: WHO; 2009. Reference Number: WHO/FCH/CAH/NCH/09.04

2. Martín A, Moreno-Pérez D, Alfayate S, Couceiro JA, García ML, Korta J, et al. Etiología y diagnóstico de la neumonía adquirida en la comunidad y sus formas complicadas. An Pediatr. 2012;76(3):162.e1-162.e18

3. Organización Mundial de la Salud [internet]. Neumonías Nota descriptiva No.331. Nov.2016 [citado 23 Jun 2017]. Disponible en: http://www.who.int/mediacentre/factsheets/fs331/es/

4. Ministerio de Salud Pública de Cuba. Dirección Nacional de Registros Médicos y Estadísticas de Salud. Anuario Estadístico de Salud 2016 [internet]. Cuba [citado 23 Jun 2017]. Disponible en: http:/files.sld.cu/dne/files/2017/05/Anuario_Estad\%C3\%ADstico_ de_Salud_e_2016_edici\%C3\%B3n_2017.pdf

5. Mosleh H, Labib JR. Accuracy of Risk Assessment Tool in Predicting Pneumonia's Outcome among Egyptian Children: Hospital Based Study. BJM Med Research. 2013;3(4):2276-87.

6. Don M, Valent F, Korppi M, Canciani M. Differentiation of bacterial and viral community-acquired pneumonia in children .Pediatr Int. 2009;51:91-6.

7. Flood RG, Badik J, Aronoff SC. The utility of serum C-reactive protein in differentiating bacterial from nonbacterial pneumonia in children: a meta-analysis of 1230 children. Pediatr Infect Dis J. 2008;27:95-9.

8. Comité de Infecciones Respiratorias de la Sociedad Latinoamericana de Infectología Pediátrica. Consenso de la Sociedad Latinoamericana de Infectología Pediátrica (SLIPE) sobre Neumonía Adquirida en la Comunidad (NAC). Rev Enf Infec Pediatr 2010;24(94):1-23.

9. Fischbach FT. Dunning MB. Blood studies. Hematology and Coagulation. In: A Manual of Laboratory and Diagnostic Test. 8th ed. Philadelphia: Linppincott William-Wilkins. 2009. p.56-183.

10. Salih KE, Salih A, El Samani FZ, Hussien KE, Ibrahim SA. Characteristics associated with severe pneumonia in under-five children admitted to emergency units of two teaching hospitals in Khartoum, Sudan. Sudan J Paediatr. 2011:11(2):25-31.

11. Borroto Gutiérrez SM, Linares-Pérez N, Toledo-Romaní ME, Mirabal Sosa M, Reyes Sebasco A, Abreu Suárez G, et al. Carga hospitalaria y poblacional de las neumonías adquiridas en la comunidad en niños menores de 5 años. Rev Cubana Pediatr [Internet]. 2017 [Citado 29 May 2017]; 89. Disponible en: http:// www.revpediatria.sld.cu/index.php/ped/article/view/218.

12. Flores Nava G, Martínez García IM, Hernández Delgado L, Delgado Fernández A. Alteraciones en la cuenta de leucocitos en un grupo de niños hospitalizados por neumonía de la comunidad. Pediatr Mex. 2011;13(3):92-5.

13. Rodríguez Cutting JM, Calero Galeas AE, Vega Mendoza D,
Pacheco Torres L. Neumonía complicada adquirida en la comunidad: Resolución de los hallazgos clínicos y radiológicos en niños. Rev haban cienc méd. 2015;14(4):438-46.

14. Brito Bartumeut M, Castillo Plasencia LJ, Vázquez Cedeño JL, Vázquez Brito L. Comportamiento de la neumonía adquirida en la comunidad en cuidados intensivos pediátricos. Hospital Héroes del Baire. Enero 2003 a diciembre 2007. Rev Cub Med Int Emerg. 2010;9(3):1797-12.

15. Rodríguez Cutting JM, Valerio Cruz AM, Vega Mendoza D, Pacheco Torres L, Castillo Oviedo R, García Sánchez JB, et al. Caracterización de la neumonía grave adquirida en la Comunidad. Rev Cubana Pediatr. 2016; 88(1):55-66

16. Tamayo Reus MC, Díaz Terán D, Leyva Peguero YE. Aspectos clínicos y radiográficos de la neumonía típica condensante en menores de 5 años. MEDISAN. 2014;18(4):523-7.

17. Moschovis PP, Addo-Yobo EO, Banajeh S, Chisaka N, Christiani DC, Hayden D, et al. Stunting is associated with poor outcomes in childhood pneumonia. Trop Med Int Health. 2015;20(10):1320-8.

18. Ardisana Cruz O, Ponce-Martínez LM, Fernández Reverón F, Francisco-Pérez JC, González-Velásquez A, Alvarez-González AI. Caracterización de las neumonías en terapia intensiva pediátrica. Rev Cub Med Inten Emerg [Internet]. 2007 [Citado 21 Abr 2016];6(3):835-49. Disponible en: http://bvs.sld.cu/revistas/ mie/vol6_3_07/mie06307.htm

19. Cruz-Robaina JC, Dorta-Correa Y, Riesgo-Mayea L, López Labrador-Piloto O, González-Díaz J. Caracterización clínico epidemiológica de la neumonía en niños hospitalizados. Rev Ciencias Médicas de Pinar del Río. 2012;16(1):158-68.

20. Moreno-Pérez D, Martín AA, Tagarro-García A, EscribanoMontaner A, Figuerola-Mulet J, García-García JJ, et al. Neumonía adquirida en la comunidad: tratamiento ambulatorio y prevención. An Pediatr (Barc) [Internet]. 2015 [Citado 12 Ago 2016]; 83(6):439.e1-7. Disponible en: http://www. analesdepediatria.org/es/pdf/S1695403314005219/S300/

21. Goldin AB, Parimi C, LaRiviere C, Garrison MM, Larison C, Sawin RS. Outcomes associated with type of intervention and timing in complex pediatric empyema. Am J Surg. 2012;203(5):665-73.

22. Sánchez-Villares L, Fernández LS, Serrano-Ayestarán O, SánchezGranados JM. Neumonías adquiridas en la comunidad en el Hospital Universitario de Salamanca. Bol Pediatr. 2015;55:25-31

23. Cevey-Macherel M, Galetto-Lacour A, Gervaix A, Siegrist CA, Bille J, Bescher-Ninet B, et al. Etiology of community-acquired pneumonia in hospitalized children based in WHO clinical guidelines. Eur J Pediatr. 2009;168(12):1429-36.

24. Korppi M. Non-specific host response markers in the differentiation between pneumococcal and viral pneumonia: what is the most accurate combination? Pediatr Int. 2004;46(5):545-50.

25. Tiwari LK, Singhi S, Jayashree M, Baranwal AK, Bansal A. Hypoalbuminemia in critically sick children. Indian J Crit Care Med. 2014;18(9):565-9.

26. Leite HP, Rodrigues da Silva AV, de Oliveira Iglesias SB, Koch Nogueira PC. Serum Albumin Is an Independent Predictor of Clinical Outcomes in Critically Ill Children. Pediatr Crit Care Med. 2016;17(2):e50-7

27. Viasus D , Garcia-Vidal C , Simonetti A , Manresa F , Dorca J , Gudiol F, et al. Prognostic value of serum albumin levels in hospitalized adults with community-acquired pneumonia. J Infection. 2013;66(5):415-23

28. Prais D, Kuzmenko E, Amir J, Harel L. Association of hypoalbuminemia with the presence and size of pleural effusion in children with pneumonia. Pediatrics. 2008;121(3):e533-8. 